\title{
Electrochemical Behaviors of Ferrocene Dicarboxylate and its Application for Heme Detection
}

\author{
Guo-Cheng Han ${ }^{1}$, Jiating Hou ${ }^{l}$, Zong-Li Huang ${ }^{1}$, Xiao-Zhen Feng ${ }^{1,2, *}$, Zhencheng Chen ${ }^{1, *}$, \\ Wenxiang Xiao ${ }^{l}$ and Shuang $\mathrm{Li}^{1}$ \\ ${ }^{1}$ School of Life and Environmental Sciences, Guilin University of Electronic Technology, Guilin \\ 541004, P. R. China \\ ${ }^{2}$ School of Chemistry and Pharmacy, Guangxi Normal University, Guilin 541004, P. R. China \\ *E-mail: fxz97118@ guet.edu.cn, chenzhcheng@163.com
}

doi: $10.20964 / 2017.07 .69$

Received: 1 April 2017 / Accepted: 15 May 2017 / Published: 12 June 2017

\begin{abstract}
Heme is an active center of hemoglobin which is a porphyrin compound containing two free carboxyl groups that may exert intermolecular interaction with ferrocene dicarboxylate which can be studied by electrochemical methods. The CV experimental results from this current study showed that ferrocene dicarboxylate had a good pair of redox peaks in $\mathrm{NaOH}$ aqueous solution and organic solvents in a quasi-reversible electrode process. There was linear relationship between current and square root of the scan rate, belonging to diffusion-controlled redox processes. The signals from the potential and current had obvious shift after the reaction with heme, especially when the redox peaks disappeared from the organic solvents. $\mathrm{Fc}(\mathrm{COOH})_{2}$ was activated to give compound $\mathrm{Fc}(\mathrm{OBt})_{2}$ with saturated structure that did not show better redox peaks due to its worse solubility, hence it didn't form hydrogen bonds with heme. DPV was used for heme assay, where the current was proportional to heme concentration in the range of 1.0-5.0 $\mu \mathrm{M}$, with $0.7 \mathrm{nM}$ detection limits.
\end{abstract}

Keywords: Electrochemical behaviors; heme; detection; hydrogen bond

\section{$\underline{\text { FULL TEXT }}$}

(C) 2017 The Authors. Published by ESG (www.electrochemsci.org). This article is an open access article distributed under the terms and conditions of the Creative Commons Attribution license (http://creativecommons.org/licenses/by/4.0/). 